\title{
Assessing risk of violent behaviour
}

\author{
George J. Lodge
}

\begin{abstract}
All British mental health professionals will be aware of several highly publicised deaths at the hands of mentally III people and will have seen the conclusions of inquiries and government reactions. To reduce the risk of future tragedies effective methods of risk assesement and prediction are needed.
\end{abstract}

The National Health Service (NHS) Executive has acknowledged how difficult it can be to make accurate judgement about future risks with the present state of knowledge (NHS Executive, 1994). In the absence of central guidance many colleagues may be mining the archives to establish what the present state of knowledge is. This paper summarises one psychiatrist's endeavours. It does not attempt a comprehensive review of the literature (see Monahan \& Steadman, 1994) but identifies the main points at issue.

\section{Violence and mental illness}

The evidence for a relationship between mental illness and violence is inconsistent. While Cocozza et al (1978) showed that the increased violent crime rate of a discharged population was entirely accounted for by those with a history of arrest and Harris et al (1993) showed a negative correlation between violent recidivism and a diagnosis of schizophrenia, Wessely et al (1994) showed increased conviction rates for violence in male patients with schizophrenia, echoing findings by Lindquist \& Allebeck (1990). In a controlled study the MacArthur Foundation (1996) found that the considerable increase in violence in their patient sample was largely accounted for by the subgroup with alcohol and substance misuse. There was a small excess of violence in the major mental illness group compared with community controls but people with schizophrenia had the lowest incidence of serious violence among the patient group. An important differentiator in the latter study is the use of self-report, in contrast with the other studies which relied on criminal conviction rates and admissions for violence.

\section{Correlates of violence}

At present there is no reliable test which will allow accurate prediction of violent behaviour in an individual. There is however research to show that the risk of such behaviour will be increased in some groups and some situations. Earlier research has been done mostly on offender populations in North America. The MacArthur Foundation (1996) recently carried out a large study on acute psychiatric inpatients.

Violent behaviour has been repeatedly correlated with (Monahan, 1981): previous arrest; history of juvenile offences; younger age; male gender (Although male sex has regularly been associated with violent recidivism, recent research had made it clear that the correlation with gender is inconsistent. Swanson et al (1990) showed little difference between violence in male and female acutely disordered populations. The MacArthur Foundation study (1996) showed slightly lower overall levels of violence and slightly higher levels of serious violence in male compared with female discharged inpatients.); race (The rate of violent crime among Black Americans is much higher than Whites. Race, however, becomes irrelevant if a history of violent crime is controlled for.): low socioeconomic status (all crime, not specifically violent crime); opiate and alcohol misuse; and low IQ.

The MacArthur study (1996) and Harris et al (1993) both identified psychopathic traits, such as impulsiveness and poor anger control, as important risk factors. The MacArthur group also identified command hallucinations as an important clinical variable.

\section{Importance of environment}

Megargee (1976) stressed the importance of the interaction between personal and situational factors. (Personal factors included motivation. internal inhibition and habit strength, and situational factors included availability of weapon, presence of onlookers and behaviour of victim.) He described the process of interaction between these factors as: classification of person as object or threat; action based on classification; person may act to protect integrity; initial stance of violence-prone person makes violence probable, his first move makes violence more probable; and reaction of victim converts probability into certainty. 
Monahan (1981) also identified: family environment (role models and social controls); peer group (role model and encouragement); stability of employment; availability of victims; availability of weapons; and availability of alcohol. Klassen \& O'Connor (1988) identified dissatisfaction with extended family as the most powerful predictor of violent recidivism in male community, mental health centre admissions. The MacArthur study (1996) added to this list frequent changes of residence and availability of social support. They also confirmed the importance of treatment compliance.

\section{Risk management}

Management can affect risk - risk assessment is thus a dynamic process. For example, reducing the likelihood of the patient coming into contact with a potential victim, improving treatment compliance or effectiveness (for example, eliminating command hallucinations) or placing a patient in a less stressful environment, or in employment, can all reduce risk.

In a high-risk patient one should have a carefully considered management plan. Three strategies should be considered: 'incapacitation'. e.g. hospitalisation or transfer to more secure accommodation; 'target hardening', i.e. warning a potential victim; and intensified treatment. When a patient defaults from treatment, efforts should be made to make contact and re-engage the patient.

Carson (1994) emphasises the need to balance risk against benefit in making risk decisions. He points out conflicts between different emanations from the British legislature. For example, the House of Commons Select Committee has said that the safety of the public must be the paramount consideration whereas the Mental Health Act highlights the importance of the patients welfare and freedom. In making a risk decision we need to be clear not only about the risk of harm but also about the potential benefits of alternative management strategies. We should balance the risk of harm to others against the risk to the patient's freedom and well-being.

Where management decisions are difficult consult with colleagues within the team, among one's peers, or outside the provider organisation.

\section{Risk assessment schemes}

Steadman \& Keveles (1972) found that the best predictor of violent behaviour was the Legal Dangerousness Scale composed of four items: juvenile criminal record: number of previous arrests; previous convictions for violent crimes; and severity of index offence. Cocozza \& Steadman (1974) found only one other significant variable; age $<50$ years. However, this still produced false positives in two out of every three cases. The Department of Correction of the State of Michigan (Monahan, 1981) showed a combination of type of index offence, behaviour while in prison and arrest before age 15, gave a $40 \%$ accurate prediction of recidivism.

Kroll \& MacKenzie (1993) published a checklist to assist clinicians in making discharge decisions in relation to risk of violence. This uses many risk factors previously mentioned but misses important items such as psychopathy, school maladjustment and non-violent offence history.

Harris et al (1993), developed a Risk Assessment Guide (RAG) based on men admitted to a secure hospital. The most powerful single predictor of repeated violence or offences involving threatened violence was the Psychopathy Check List score (Hare, 1991; Hare et al, 1991). Fiftyfive per cent of those with high scores on a combination of 12 variables showed repeated violence. This, however, means that of those who had high scores, and thus were predicted to reoffend, $45 \%$ did not re-offend, also $40 \%$ of repeat offenders had low scores and thus were not predicted to reoffend.

Using Harris's data Webster et al (1994) showed an impressive correlation between RAG scores and risk of recidivism. They recommended combining the RAG with a clinical appraisal in their 'Violence Prediction Scheme'.

In a further development Webster et al (1995) produced a structured clinical assessment, the HCR-20, which attempted to marry historical, clinical and risk management variables. This uses clinical concepts identified in the RAG and elsewhere. It is not, however, as yet, a validated actuarial approach. It is important for providers to produce a structured risk assessment procedure that is appropriate to the patient population and setting. In my own Trust a modification of the HCR-20 approach is being used as a guidance scheme for clinicians rather than as a rigid prediction scheme. Its use and predictive power will subsequently be audited.

\section{Using information}

Four types of information should be considered: records of past treatment; records of current treatment; information from interviewing the patient; and information from significant others. A clinician needs to know what information is relevant, how to collect it and use it to estimate risk. Proper documentation is vital (documentation of interviews, consultation, decisions and decision rationale), and if the 
clinician is not the ultimate decision-maker effective communication to those who are responsible is essential.

Monahan (1993) points out that it is not enough to learn the basic concepts and classic findings in the field of risk assessment once and consider one's education complete. He suggests the most efficient form of risk education may be to have someone charged with the role of risk educator keeping up-to-date through formal programmes and by reviewing relevant journals. This includes keeping up-to-date with legal developments.

\section{Policies}

While making risk management policies explicit has advantages such as promoting clarity of thought, encouraging consistency of application and bringing novice clinicians more quickly up to standard, it also carries its own risks. If policies are not followed then the provider organisation will be open to criticism and litigation. Guidelines should reflect the minimum standards necessary for competent professional practice and not ideals. Forms should assist the clinician in recording relevant information and staff should be educated and their compliance subject to audits. Once drafted, it would be advisable to have a policy reviewed by other clinicians from comparable facilities elsewhere.

It would be futile to apply predictive schemes to all psychiatric patients, given the low incidence of serious violence in our general psychiatric population. The lower the base rate of a behaviour in a population the lower the accuracy of any predictive test.

\section{Damage limitation}

Sometimes things will go wrong. This does not mean a mistake has necessarily been made, sometimes low probability events do occur. Monahan warns against two common maladaptive responses: tempering with the record and talking through feelings of guilt in public, or writing injudicious and damning comments on the case record after the event.

\section{Conclusions}

(a) Work is proceeding in this area but at present there is no test that can reliably be used to predict violence.

(b) It is important to make judgements which are balanced and based on available evidence about the individual and on research findings. (c) It is inappropriate to make risk assessments on all patients as evidence suggests that even with the best methods the reliability of such predictions would be poor. It would be sensible to undertake formal risk assessments only if the patient's history, behaviour or symptoms give cause for concern, for example when there is a history of violence, threatened violence or implied threats of violence (e.g. hallucinations urging violence). A further risk assessment should be undertaken if escalating acts, threats or ideas of violence suggest an altered risk or when discharge from hospital is considered for a patient who has already been identified as an appreciable risk.

(d) Informed clinical decisions taken in the light of the appropriate information (past records, current records, patient interviews and information from relevant others) should be made. Decisions should seek to balance risks and benefits and the information, decision and those involved/ consulted in the decision-making process should be recorded in a structured format. The use of validated actuarial methods of prediction should be incorporated when available.

(e) Where decisions are particularly difficult consultations should be sought either within or outside the health care provider organisation.

(f) The provider should have a policy on risk assessment which represents the minimum necessary compatible with current good practice. The policy should be promulgated in an organised way to all clinicians, and there should be audit of its use.

(g) A clinician should be identified with responsibility for keeping the policy up to date.

\section{References}

CARSON, D. (1994) Dangerous people: Through a broader conception of 'risk' and 'danger' to better decisions. Evidence, 3, 51-69.

CocozzA, J. \& STEADMAN, H. (1974) Some refinements in the measurement and prediction of dangerous behaviour. American Journal of Psychiatry. 1012-1020.

-. MELICK. M. \& STEADMAN, H. (1978) Trends in violent crime among ex-mental patients. Criminology. 16, 317334.

HARE, R. D. (1991) Manual for the Hare Psychopathy Checklist (Revised). Toronto. ON: Multi-Health Systems. -. HART, S. D. \& HARPUR. T. J. (1991) Psychopathy and the DSM-IV criteria for anti-social personality disorder. Journal of Abnormal Psychology. 100. 391-398. 
HARRIS, G. T., RICE, M. E. \& QUINSEY, V. (1993) Violent recidivism of mentally disordered offenders: The development of a statistical prediction instrument. Criminal Justice and Behaviour, 20, 315-335.

KLASSEN, D. \& O'CONNOR, W. A. (1988) A prospective study of predictions of violence in adult male mental health admissions. Law and Human Behavior, 12, 143-158.

KROLL, J. \& MACKENZE, B. (1993) When psychiatrists are liable: risk management and violent patients. Hospital and Community Psychiatry, 34, 29-37.

LINDgVIST, P. \& ALLEBECK. P. (1990) Schizophrenia and crime: a longitudinal follow-up of 644 schizophrenics in Stockholm. British Journal of Psychiatry. 157, 345-350.

MACARTHUR FOUNDATION RESEARCH NETWORK ON MENTAL HEALTH AND THE LAW (1996) Violence, Competence and Coercion: Pivotal Issues in Mental Health Law. Oxford: Wadham College.

MEGARGEe, E. (1976) The prediction of dangerous behaviour. Criminal Justice and Behavior, 3, 3-21.

Monahan, J. (1981) The Clinical Prediction of Violent Behavior, Crime and Delinquency Issues (A monograph series). Rockville, MD: US Department of Health and Human Services, Public Health Service, Alcohol, Drug Abuse and Mental Health Administration, National Institute of Mental Health.

- (1993) Limiting therapist exposure to Tarasoff liability: guidelines for risk containment. American Psychologist. 48. 242-250.
- \& STEAdMAN, H. J. (eds) (1994) Violence and Menta Disorder: Developments in Risk Assessment. Chicago: University of Chicago Press.

NHS EXECUTIVE (1994) Guidance on the Discharge of Mentally Disordered People and their Continuing Care in the Community. NHS Executive, HSG(94)27. London: Department of Health.

Steadman, H. \& Keveles, C. (1972) The community adjustment and criminal activity of Baxstrom patients: 1966-1970. American Joumal of Psychiatry. 3, 376-386.

SWANSON, J., HolZER, C., GANuU, V., et al (1990) Violence and psychiatric disorder in the community: Evidence from the Epidemiologic Catchment Area Surveys. Hospital and Community Psychiatry, 41, 761-770.

WEBSTER, C. D., HARRIS, G. T., RICE, M. E., et al (1994) The Violence Prediction Scheme: Assessing dangerousness in high risk men. Toronto, ON: Centre of Criminology. University of Toronto.

- EAVES, D. DOUGLAS, K, et al (1995) The HCR-20 Scheme: The Assessment of Dangerousness and Risk. Burnaby. BC: Simon Fraser University and Forensic Psychiatry Services Commission of British Columbia.

Wessely, S. C., CAstre, D., Douglas, A. J., et al (1994) The criminal careers of incident cases of schizophrenia. Psychological Medicine, 24, 483-502.

George J. Lodge, Consultant Psychiatrist, Green Lane Hospital, Devizes, Wiltshire SN10 5DS

\section{Prevention of Anxiety and Depression in Vulnerable Groups \\ Joanna Murray}

The scope of this review, commissioned by the Department of Health, is the common mental disorders of anxiety and depression occurring in adults in the community. It considers the possibilities for prevention in primary care. This combination of basic conceptual and research information provides a practical framework of preventive strategies for the primary care team. Social factors in aetiology are examined in detail, and epidemiological data is used to consider vulnerability factors and to identify high risk groups. There is also a thorough review of risk for common mental disorders. Ł7.50, 112pp., 1995, ISBN 0902241877

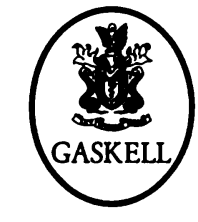

Gaskell books are available from good bookshops and from the Publications

Department, Royal College of Psychiatrists, 17 Belgrave Square, London

SW1X 8PG (Tel. +44(0)171 2352351 , extension 146).

The latest information on College publications is available on the

INTERNET at: http://www.demon.co.uk/rcpsych/ 